\section{Psychiatric training and research in Ireland}

Dear Editor - Nkire et al' in their editorial mention 'not being able to obtain a large enough sample' as an obstacle faced by basic specialist trainees when undertaking research during their years on training schemes. This may indeed represent an obstacle when trainees restrict themselves to the quantitative research paradigm. But what of the qualitative paradigm? As Brown et $\mathrm{al}^{2}$ note, the split between quantitative and qualitative research is pronounced in health sciences. This has been encouraged in part by the hierarchy of research methods set out by the evidenced-based medicine paradigm, ${ }^{3}$ but also it would seem, by a failure of postgraduate training schemes to consider the qualitative paradigm worthy of mention in their curricula. ${ }^{4}$ This is a pity, for in psychiatry probably more so than in any other field of medicine, quantitative research is often insufficient to fully explain the phenomenon under investigation. For example, can 'recovery' from a depressive illness be neatly defined as a 10-point improvement on a Hamilton Rating Scale? Such a complex phenomenon (and there are many more encountered in 'routine' clinical practice by the trainee) is perhaps best investigated through a combination of both quantitative and qualitative research methods. Sampling in qualitative research is purposive, as subjects can be chosen deliberately in order to test a particular theoretical premise. The purpose of sampling in qualitative research is to identify cases that possess relevant characteristics for the question being considered. Therefore one or two in-depth interviews or focus groups may be sufficient for a trainee to derive a wealth of data inaccessible through quantitative research methods. This may hold particular relevance for the trainee wishing to undertake a research project over the course of a six month hospital rotation, overcoming the 'obstacle' mentioned by the authors. In such a context qualitative research should not be seen as a 'quick alternative' to quantitative research but rather a means of producing a detailed sample to enable a coherent explanation of the phenomenon under study. Good qualitative research is time intensive.

Lest we forget, and as noted by Brown et $\mathrm{al}^{2}$ in their excellent summary of qualitative research methods, some of the most seminal work in the field of psychiatry has its roots in qualitative research. Freud developed the 'science of psychodynamics', using an iterative process with constant feedback between theory and observation which he meticulously recorded. ${ }^{5}$ Phenomenology, which Jaspers defined as "the systematic study of subjective experience" used methods that would today be included under qualitative research. ${ }^{6}$

I would argue that the goal of qualitative clinical research is that which is most relevant to a new trainee: to paint a complete picture of the problem under investigation. Which areas - biological, social, psychological and economic - are important in understanding the impact on the individual of the problem under study? The paradigm of qualitative research is entirely consistent with the biopsychosocial perspective at the heart of modern training in psychiatry, an issue those involved in the development of a new postgraduate curriculum for the College of Psychiatry of Ireland should be mindful of.

The authors state that the drive towards the evidenced- based medicine has recently made the focus upon research even more acute. ${ }^{1}$ I would view their definition of evidencedbased medicine (that which seeks to integrate best research evidence with clinic experience and patient values in order to ensure the best outcome for patients) as being by its nature dependent upon both quantitative AND qualitative research initiatives.

Kieran O'Loughlin

Senior Registrar in Psychiatry St Vincent's University Hospital

Dublin 4

References

1. Nkire N, Edokpolo O. Psychiatric training and research in Ireland, the trainee's perspective. Ir J Psych Med 2011; 28(1): 3-5.

2. Brown C, Lloyd K. Qualitative methods in psychiatric research. Adv Psychiatr Treat 2001; 7: 350-356.

3. Sackett D, Richardson WS, Rosenberg Ws et al. Evidenced Based Medicine: How to Practice and Teach EBM. London: Churchill Livingston, 1997.

4. Royal College of Psychiatrists (2006b) Appendix 1: Syllabic curriculum content: Summary of Are of Summary of Areas of Core Medical Knowledge Underpinning Specialist Training in Psychiatry. London: Royal College of Psychiatrists. www.rcpsych.ac.uk/pdf/Appendix\%20
1\%20-\%20Syllabic\%20content.pdf 1\%20-\%20Syllabic\%20content.pdf

5. Kvale S. The psychoanalytic interview as qualitative research. Qualitative Inquiry, 1999; 5: $87-113$

6 . Jaspers C. The phenomenological approach in psychopathology. British Journal of Psychiatry 1968; 114: 1313-1323.

\section{Reply to Dr O'Loughlin's letter}

Dear Editor - We would like to thank Dr O'Loughlin for his comment on our editorial. In referencing Fogel ${ }^{1}$ on his mention of 'not being able to obtain enough a large enough sample' as a factor contributory to basic psychiatric trainees' (BSTs) difficulty with research, we viewed this factor as one of a myriad of problems facing BSTs rather than a primary cause of the difficulty.

We believe that the primary purpose of psychiatric research should be to answer relevant questions in the field of psychiatry. Whether it is evaluative or driven by hypothesis is a moot point. However it must adopt the methodology suitable for the question it seeks to answer. As such the debate that Dr O'Loughlin alludes to regarding quantitative and qualitative research, although relevant, should not be an impediment to new research by psychiatric trainees. What should matter is: Are the relevant questions being asked by psychiatric researchers? Are students being taught and empowered to ask the right questions? If they are, are they adopting the right methodology in seeking answers to these questions?

We believe that qualitative and quantitative research methodologies are both very relevant in psychiatry, and act in tandem to facilitate greater understanding of mental illness. However, they must each be applied appropriately in the quest for answers to questions. There should not be a drive to denigrate quantitative and/or qualitative research, or to shoe-horn appropriate questions into inappropriate methods. Hopefully, as fledgling psychiatric researchers/trainees explore their potentials they will gain more confidence and insight into asking deeper questions. This will in turn help them to adapt qualitative methods in deriving more hypotheses for further research, to the benefit of psychiatry.

We would echo that where there has been less of an emphasis by postgraduate training schemes to teach qualitative research methods, this should be redressed. 
Psychiatry, which is both a health science and a social science, is centrally placed to richly benefit from qualitative and quantitative research methods.

Nnamdi Nkire,

Clinical Research Fellow/Registrar, St Davnet's Hospital, Monaghan, Ireland

Osamede Edokpolo,

Department of Psychiatry,

St Elizabeth's Hospital, Washington DC,

USA.

Reference

1. Fogel J. Research as part of the career of a psychiatrist entering clinical practice. Psychiatric Bulletin 2009; 33: 269-272.

\section{A model for primary mental healthcare in Ireland}

Dear Editor - We read with interest Kierans and Byrne's paper and presentation of a model for primary mental health care in Ireland. ${ }^{1}$ We welcome the advancement of the debate on primary care mental health. We agree there is a need for further developments within primary care, and the model proposed has many benefits. However we can also see some difficulties and advise a more collaborative approach between primary and secondary care.

The primary care practitioners the authors refer to are similar to the graduate mental health workers, who have been introduced as part of the Improving access to psychological treatments (IAPTS) in the UK. There is evidence that GPs do not trust the graduate workers. ${ }^{2}$ Fletcher et $\mathrm{al}^{3}$ described how a collaborative approach would ensure the role of the graduate mental health worker was embedded into the service, but they described many problems in setting up the posts, with graduates often unsupported and the process not having managerial support. Farrand et al ${ }^{4}$ conducted a qualitative evaluation of the role, and concluded that early difficulties were linked to inappropriate referrals and lack of clear role definition. They advised it was a valuable addition to a stepped care approach to mental healthcare in primary care. However, one of the key determinants of the impact of enhanced primary care mental health resources is the extent and quality of integration and communication at the interface between primary and secondary care. Lester et $\mathrm{al}^{5}$ found that patients assigned mental health workers in primary care were more satisfied with their care than controls but outcome was no different. Tylee and Walker ${ }^{6}$ use this finding to emphasise that 'bolting on' extra resources to existing care strategies does not improve outcome. Tey argues for systemic change, using collaborative care to introduce a chronic disease model for mental illnesses.

There is a risk the model proposed may result in a greater burden on specialist mental health teams. Consultation liaison models, where a consultant psychiatrist attends the general practice every six to eight weeks, has been shown to improve the appropriateness of referrals and improve the detection of those with mental health problems. ${ }^{7}$ We have found these meetings can be used to inform GPs on the availability of community resources, including self help groups, and recommend that any quasi specialists in mental health would be incorporated into these meetings.
We would be interested in knowing of other practices throughout the country, where there is greater liaison between primary care and secondary care, or where mental health professionals are working in primary care.

Vincent Russell, Martina Kelly, Joint Chair ICGP CPsychl Forum for Mental Health in Primary Care Dublin, Ireland

References

1. Kierans J, Byrne M. Ir J Psych Med 2010; $27(3):$ 152-156

2. Bower $P$, Rowland N. Effectiveness and cost effectiveness of counselling in Primary Care. Cochrane Database of Systematic Reviews, Issue 1, 2009

3. Fletcher J, Gavin M, Harkness E, Gask L. A collaborative approach to embedding graduate primary care mental health workers in the UK National Health Service. Health \& Social Care in the Community; 2006; 16(5): 451-459

4. Farrand P, Duncan F, Byng R. Impact of graduate mental health workers upon primary care mental health: a qualitative study. Health \& Social Care in the Community 2007; 15(5): 486-488.

5. Lester $\mathrm{H}$, Freemantle $\mathrm{N}$, Wilson $\mathrm{S}$ et al. Cluster randomised controlled trial of the effectiveness of primary care mental health workers. Br J Gen Pract 2007; 57(536):196203.

6. Tylee A, Walker P. We need a chronic disease model for depression in primary care. B $J$ Gen Pract 2007; 57(538): 348-350.

7. Russell V. Liaison psychiatry in rural general practice. Ir J Psych Med 2003; 20(2): 65-68.

\section{New long-stay psychiatric in-patients: a comparison of UK and Irish national audit}

Dear Editor - The above mentioned interesting study by Daly and Walsh, on new long-stay Irish patients in 2006; which was published in Ir J Psych Med 2009; 26(3): 134-139. The author thanks Daly and Walsh for their efforts to report on the first national level Irish study on NLS psychiatric in-patients.

This letter aims to compare the Irish study with much cited UK audit by Lelliott in $1992^{1,2}$ so as to stimulate further discussion and promote further research.

The Irish study covered all the NLS psychiatric in-patients coming from catchment population of $\sim 4.4$ million (Ireland population census, 2006); while the UK audit 1992, covered; estimated population: 26\% of England; $7 \%$ of Scottland, $41 \%$ of Wales; $82 \%$ of Northern Ireland; served by 59 mental health services of NHS (total catchment population 15.2 million).

The UK study ( $\mathrm{n}=905$ ) was cross-sectional, by census; while Irish study not only identified (by census on $31 / 03 / 2006)$, described NLS sample $(n=460)$, but also surveyed it after one year reporting that over two thirds of NLS patients $(n=315)$ were still residing at psychiatric units or hospitals, and $20 \%,(n=64)$, had become old long-stay patients (stay five years and over).

The UK study included patients aged 16-64 years, staying over six months up to three years while the Irish study included patients aged 16 years and over (and had 40\% patients ( $n=185$ ), aged 65 or over), with stay of one year to less than five years.

It is interesting that the UK study included a lower limit of long-stay as six months (rather than the traditional one year or over, as in the Irish study). This was because many participating units had a small number of acute beds and stay over six months was undesirable there; while the upper limit of three years was chosen, as the six-month lower limit for length of 